\title{
Organized Online Learning of Students in Universities and Schools: Didactics and Methodology
}

\section{Aprendizaje en Línea Organizado de Estudiantes en Universidades y Escuelas: Didáctica y Metodología}

\section{Lyudmila Petrovna Gadzaova}

Doctor of Pedagogy, Professor of the Department of Foreign Languages for Non-linguistic Specialties of the North Ossetian State University (SOGU) named after K.L. Khetagurov,

Vladikavkaz, Russian Federation

Professor of the Chechen State University, Grozny, Russian Federation https://orcid.org/0000-0001-9558-0818

\section{Elena Valentinovna Goverdovskaya}

Doctor of Pedagogy, Volgograd State Medical University, Pyatigorsk, Russian Federation https://orcid.org/0000-0001-5987-3277

\section{Esmira Dokuevna Alisultanova}

Candidate of Physical and Mathematical Sciences, Doctor of Pedagogical Sciences, Associate Professor, Director of the Institute of Applied Information Technologies, Professor of the Grozny State Oil Technical University named after Academician M.D. Millionshchikova,

Grozny, Russian Federation https://orcid.org/0000-0002-2565-5615

\section{Natalia Anatolievna Moiseenko}

Candidate of Pedagogical Sciences, Associate Professor, Head of the Department of Information Technologies of the Grozny State Oil Technical University named after Academician M.D. Millionshchikova, Grozny, Russia https://orcid.org/0000-0003-3598-7012

*Correspondencia

Email: $\underline{\text { nosu@nosu.ru }}$ 


\section{Summary}

This article discusses the urgent aspects of online learning didactics. They are comprised of, for instance, organization and methods of organized learning, main principles of actions aimed at practical orientation; their objective is combination of the methods of distance learning, formation of efficient skills of students with social mediation, analysis of reasons of errors and their correction, pursuance of success in relevant areas. Organized online learning also provides opportunity for students to use all advantages of digital technologies: flexibility, individual distribution of learning duration, compatibility with other forms of occupation. In addition to digital know-how, organization of learning and independent work of distant students can develop self-discipline, sustainability of acquired skills. Students can use various digital sources of information available under various conditions in addition to that organized under the management of distance learning teacher.

Keywords: Online Learning, Organized Learning Process, Operating Under Certain Conditions, Cognitive, Communicative, Interpersonal Approaches, Sustainable Skills.

\section{Resumen}

Este artículo analiza los aspectos urgentes de la didáctica del aprendizaje en línea. Se componen de, por ejemplo, organización y métodos de aprendizaje organizado, principios fundamentales de acciones dirigidas a la orientación práctica; su objetivo es la combinación de los métodos de aprendizaje a distancia, la formación de habilidades eficientes de los estudiantes con mediación social, el análisis de las causas de los errores y su corrección, la búsqueda del éxito en las áreas relevantes. El aprendizaje en línea organizado también brinda a los estudiantes la oportunidad de utilizar todas las ventajas de las tecnologías digitales: flexibilidad, distribución individual de la duración del aprendizaje, compatibilidad con otras formas de ocupación. Además del conocimiento digital, la organización del aprendizaje y el trabajo independiente de los estudiantes distantes pueden desarrollar la autodisciplina, la sostenibilidad de las habilidades adquiridas. Los estudiantes pueden utilizar diversas fuentes digitales de información disponibles bajo diversas condiciones además de la organizada bajo la dirección del profesor de educación a distancia.

Palabras clave: aprendizaje en línea, proceso de aprendizaje organizado, funcionamiento en determinadas condiciones, cognitivo, comunicativo, enfoques interpersonales, habilidades sostenibles.

\section{Introducción}

In the existing world with its disappearing borders, the educational skills in combination with interpersonal, communication, and language aspects are more important for people than ever. Digitization penetrates into all spheres of society. The requirements related with it also affect all universities and schools. Teachers actively develop efficient concepts and strategies of further development of education, using new technologies, proprietary methods in a thoughtful and purposeful manner, making their contribution into optimization of school and fundamental academic education. On the background of increasingly digitized professional world, the digital competences are required formed upon interaction of scientists, teachers, and students. As shown by our teaching practice, online learning can be successful upon strict organization of the process, which includes continuous monitoring and researching. The researching aspect prevails, since the learning offers are not likely to stand still, they will expand the process of cognition for students, and the use of digital technologies means transformation of conventional multilevel education in favor of innovative hi-tech online learning methods, where the required modernization should be combined with organization. The organized education on the basis of digital technologies is aimed at:

- revealing the students' potential in order to learn the proposed technologies; 
- improvement of motivation to distance learning and enhancement of its quality by equal engineering opportunities for purposeful support of teaching and procurement.

Implementation of the formulated tasks is based on wide cognitive skills, which, as known, refer to any activity accompanied by demonstration of acquired knowledge and its continuous improvement and updating, including perception, memorization, thinking, and practical use. We believe that cognitive capacities are also the concepts of human intellectual constituent based on memory content, classifying any situations, evaluating and saving them.

\section{Methods}

Digital media in teaching improve availability of wider scope of learners; provide opportunities of feedback in learning platform; create authentic communication situations, which are very problematic during face-to-face classes or impossible at all; facilitate efficient satisfaction of individual demands of learners and provide more efficient learning control in comparison with face-to-face process.

The use of technical aids for group online seminars with voice communications, where students can hear and see not only the teacher but their peers, as well as the use of methods of individualization are implemented in technical, didactic, and organizational aspects and are aimed at successful learning, its continuous optimization oriented at better adaptation of learners to distance learning, at assistance in purposeful and efficient use of digital technologies for knowledge acquisition, at ability to manage independently the new methods applying them reasonably. The organized controlled distance learning should be developed, its efficiency should be improved, this is aided by integration of quality management system, purposeful stimulation of formation of competences of academic education in digital format with consideration for requirements of the digital era and requirements of state standards of education.

\section{Results}

It is quite obvious that the learning process in educational establishments as well as its subsequent use should be meaningful, based on students' inherent spontaneity, curiosity, readiness for the new. However, taking into consideration that this potential is characterized by its individual personalized indices, limits and norms, the learning process and introduction of knowledge, concentration on specific types of learning require for time, which is also characterized by limitations. This time is insufficient in a wider context to accommodate in the conceptual structure of teaching an appropriate structured thinking tailored to a specific student, and to build his logical memory by means of teaching.

That is why the online learning is a specially organized process operating under certain conditions. It is important for students to understand conceptually the intelligence level of own empirical experience; their own and the teacher's perception of it defines which processes would facilitate the material mastering, where the influence of cognitive structure of knowledge acquisition is obvious; the logical memory of person is responsible for it. The attitude and motivation of students to develop their capabilities for more intensive, successful, energetic professional activity determine both the quality of their participation in organized educational process and their readiness to learn independently.

Another important factor includes current requirements, prevailing forced distance learning; the labor market, which has modified accordingly, creates significant limitation of time and funds for learning. The teachers and students have mastered well and with great dedication the transition from face-to-face to online learning caused by the pandemic.

However, continuous impact supplements the set of external factors of motivation decrease. The internal motivating factors originate from individual consciousness of students, 
belief in usefulness and benefits of specific knowledge and technological training. In this regard, it is also relevant to organize, to manage the process consciously and according to individual and current demands of students.

Despite unusual and seemingly lost year of 2020, the Russian system of education developed the required conditions for maximum efficient execution of academic and scientific activity of teachers and students. With consideration for the organized valid rules, restrictive measures are applied to provide the specific required learning formats (face-to-face/nonface-toface teaching), combined types of practical and online teaching are proposed with accounting for health care of students and teachers.

Distance learning is an alternative, when it is applied forcibly, and classical face-to-face and nonface-to-face modern forms of virtual learning are interconnected by means of new digital information and communication aids; herewith, there exists mixed learning: training and distance format, when training takes place over the Internet. «Der Einsatz verschiedener digitaler Anwendungen und die damit verbundenen Sozialformen weisen zunächst auf die Beibehaltung traditioneller Strukturen in der Hochschullehre hin, lassen aber auch methodische Veränderungen erkennen: Einzelarbeit hat an Bedeutung zugenommen, was eng mit dem Einsatz von multimedialen Anwendungsformen zusammenhängt. Das Selbststudium gewinnt durch die erweiterten Visualisierungs-, Interaktions-möglichkeiten von Anwendungsformen.» ("The use of various digital applications and the associated social forms initially indicates at the retention of traditional structures in university teaching and also reveals methodological changes: individual work has increased in importance, which is closely related to the use of multimedia application forms. Self-study is gaining in importance due to the extended visualization, interaction possibilities of application forms.") (Rinn and Bett, 2004).

Under such conditions, the success of learning is most often determined by the tasks of teacher's control and students' self-control.

The learning material can be deepened in supplemental events of face-to-face education. The time consumptions are evaluated realistically, and only very high level of discipline and realistic estimation of own resources of both parties lead to success.

Online learning provides numerous advantages, probably, the greatest one of them is flexibility because, irrespective of our life, the digital learning is aimed at combination with all unpredicted circumstances.

Online learning provides higher independence and space for individual choice in comparison with face-to-face learning.

Another important advantage of digital learning is its safety. It is guaranteed during online learning, which finally occurs quite regularly. This also preserves usual way of life, which is an important aspect for many participants in the learning process.

Organized online learning also allows students to use all advantages of digital technologies: unlimited scope of information, flexibility of its structuring and mastering, individual distribution of time and learning duration. In addition to digital know-how, organization of independent distance working of students can develop their self-discipline, promote expansion of their interests, intelligence and general culture of education using various tools available under various conditions: exchange by e-mail or educational platforms, delivery of performed assignments for examination, etc.

The greatest problems of online learning are the necessary self-discipline and management of time, getting used to organization of assumed calm in home office. However, it should be stressed that the students have no skills of organized learning or have them in different extent. Organization in learning depends not completely on the available cognitive and competence factors. The students mostly can acquire basic skills and knowledge of interpersonal communication. The difference in high-quality mastering of the skills in distance mode depends mostly on students' intelligence. In practical teaching, when planning or 
conducting classes, we apply didactic decisions, which are comprised of target, concept, principles and strategies of learning, learning materials, their typology, type of control. This choice of didactic decisions is based on our proprietary methods of organization of distance learning by means of digitized aids. This shows good results, supporting and expanding interdisciplinary competence approach in modern methodology of learning, allowing further development of online learning, making a prerequisite condition the knowledge of social conventions and unanimity in comprehension of the applied interactive aids. However, we believe that the backbone aspect is the formation of understanding by students of their own point of view; their active and independent development and personality formation using the proposed concept and implemented strategies. The teacher has three tasks: to organize presentation of learning material and other information to students in various forms (lectures; texts; pictures for description, understanding and explanation (in own perception)); to explain the procedure of comprehension of common and peculiar rules under special remote conditions and then to allow the students to assimilate the proposed information, to think, to reason, to communicate; to provide to students some time for control.

This process has already proved its efficiency being based on modern didactic, theoretical methods and demonstration of acquisition of required professional, interpersonal, communicative skills, which finally, as confirmed in practice, is the individual achievement of both the teachers and the students.

The teaching objective is to orient and to promote the learning.

A serious problem of methodology is the personality of teacher, the role of technologies and teaching aids. The acquired experience of teaching demonstrates that the distance learning is a complicated and long-term process for many students. This is especially obvious, when certain topics cannot be practically presented, i.e., when there is no demonstration of their actual use, practice, educational environment in conventional face-to-face understanding; and under such conditions, the practical skills of professional orientation can hardly be developed.

Each learning process requires for maximum planning, initial point, targets and stages, relevant learning strategy, learning materials (aids, portfolio, etc.), and control. It should be determined that the learning objective is important: not expansive information about profession but its practical context, that is, ability to orient in its important aspects, to use duly the products of education.

The distance learning should not be unilateral intermediacy by the teacher but, rather, bilateral dialogue between the teacher and students to create the atmosphere of mutual understanding, where the main required structures gradually become transparent. Manifestation of such transparency is a precondition for growing participation and self-determination of students during learning, it determines prospects of further positive results and, respectively, promotes development of their orientation at the future. This is achieved when the teacher possesses distinct concept, when the teacher can easily and confidently present the topic, present his teaching method clearly, fill it with practical meaning, achieve good results, create preconditions for further creative enhancement.

It is impossible to rely on self-control of students at this stage of our education system being without great successes at the way to target, the teacher should monitor the learning process and duly control and direct the course of educating actions. Therefore, the organized learning requires for concentration and consistency at the level of initial conditions and targets (didactics), as well as at the level of subsequent implementation of actions (methodology) in close interrelation without subdivision, which is the most important. Then, all actions lead to progress in achievement of the desired targets.

The scientific methodology of learning is aimed at increase in also very important cognitive reflection, sustainable level in teaching of theory and execution of practical actions (optimization of practice). Despite numerous factors influencing learning quality, complexity of implementation of theoretical substantiations, the teacher cannot refuse his practical objective 
and targets only because the activity is based on fluctuating grounds. That is why the methodology of distance learning is the practically-oriented science, the science of specific actions based not only on empiricism and precise knowledge but also on experiment, practical experience and, to some extent, on gaming imagination, observation and understanding, local orientation. Its most important criterion is substantiation of its results: its practicality, success, persuasive power of impact, prognostic value in educational practice, opportunity to transfer its recommendations to various teachers and their use in various educating situations.

The teaching experience demonstrates that under favorable conditions, even the weaker students could possess certain knowledge and skills of professional activity, and, more or less, master interpersonal communication. Sometimes it is required to select methods corresponding to their adaptation, otherwise, they will be unsuccessful. Organization and management of learning mean that most students have a chance that the learning will be successful; however, it is difficult to avoid the situation when single students cannot achieve due competence to a sufficient extent.

Therefore, the learning methods should be organized with consideration for various capabilities of students. There is no single universally correct methodology of teaching, but it can be diversified. The teacher is guided by the general learning objective, tasks, and educational obligations but can make certain independent methodological decisions, which are more suitable for the selected learning concept. «Integration of mobile and social technologies creates new opportunities for e-learning, for instance, in the form of technologies of augmented reality, which allow to overlay information above image of real world and provide new methods of access to data in Internet during learning» (Babanskaya et al., 2015). Somewhat unsuccessful students understand the significance of professional competence, cognitive and intellectual development, trying to advance in this direction, applying a lot of efforts, expecting a comparable success. Monitoring of learning shows that students are very different in many ways: in their knowledge, in their interests, in motivation, talents and skills, strategies and rates of learning, thus, the approach to learning task is different. They use their internal and external resources in different ways; hence, the results are different.

That is why we plan to work on various psychological and pedagogical strategies in university so that to obtain results when underachieving students, who try to overcome this underachievement, capable to execute common cognitive operations (including sensory perception, articulatory skills, cognitive skills for abstraction and generalization, structuring of rules, etc.), without which it is impossible to study, can satisfactorily perform their preset functions. In future they should continuously improve, maintain the acquired knowledge, since the ability to preserve mechanically obtained knowledge, as psychologists believe, is restricted without clear and consistent organization of this knowledge in memory, contrary to the students who firmly mastered the principles of memorization of specific information and adsorb new knowledge as sponge. Resulting efficiency of such memory is high. However, mechanical memorization playing important role at initial stage, without intellectual challenge, long-term prospect, hence, the issue of failure, requires for certain continuation, strengthening, correspondence to the program of online learning.

The issue of responsibility for teaching is regulated respectively: hardworking talented students with macrostrategy are successful, and the acquired skills most probably (and this is confirmed in practice) will accompany them and promote their future professional success. Other participants in the learning process with mechanical replenishment of proposed knowledge will get good mark: fair award for successes. Organized online learning is focusing of their attention on specific aspects of meaning, subject content of the proposed learning material in cognitive context. Conceptually this is coordinated with their integration into modern way of living, enhancement of their successes in interpersonal and intercultural competence.

Taking into account that successes in learning can be based only on the use of authentic learning materials, presentations, visual demonstration of actual essence of their content, situations, reinforcement of this approach in educational process is provided due to analysis of 
errors and drawbacks, both planned and resulting from life experience of students and teacher, thus achieving the targeted level.

Pedagogical conditions are formed for expected subject, communicative, and intercultural skills during online learning, which continue to develop, to improve, being oriented at actual intercultural subjects and issues, increasing challenges of the learning. Respective didactic and methodological digital technologies provide performance of learning at planned level. In this case, we face the significant requirements to specific didactics of learning by teacher and implementation of cognitive intellectual capabilities by students. The use of original materials upon didactic planning develops and forms the thinking strategies of students and promotes activation of respective learning actions and interpersonal communication. Visibility of actions, their reality and efficiency are substantive and relevant.

The quality and practical efficiency of learning evaluation are based on successes achieved, on the one hand, by enhanced and active participation of students during online classes, and on the other hand, by didactic proprietary methodology and understanding of significance of acquired skills, flexibility of offers from learning methods: more information is generated and available in the world, and not only the scope of individually acquired knowledge. Support can serve for provision of higher level of individuality so that to achieve better feedback, motivation to better studying. Therefore, productive and independent approach is supported.

Organization of teaching of basic knowledge is indicative from various points of view; reflection of didactic methods and principles directed both at students and teachers expands the currently important competence and ability to productive dialogue and polylogue during learning. Selection of methods and aids, specific tasks and structured systematic content, as well as respective didactic principles and specific recommendations for organized learning with respective investigations comprise the mechanism of online learning.

\section{Conclusion}

Organization of time and information, support of digital aids become important aspects of development of technological infrastructure of educational environment and establishment of educational culture of students, which lead to sustainable results. Online learning is supported by greater visualization or attention control. Using virtual realities, it is possible to achieve even motivation effects resulting from abundant information, plunging into virtual environment as if it is nearly real.

If we want to make the potential of distance learning really fruitful, then it is required to organize learning using digital technologies in terms of efficiency, opportunity to acquire decontextualized knowledge suitable both for groups and individual absorption of information. Organized learning management should include pragmatic approach to structuring of integrated knowledge, based on organization of specific planned actions on knowledge acquisition, related with demand for new educational culture and representing acquisition of significantly higher chances of distance, intellectual, pragmatic education.

The applied technology requires for interactivity, facilitating purposeful attraction of attention and stimulation of knowledge exchange by means of cooperation and intention to interact by all participants in learning. «Weiterbildungs- und Qualifizierungsprogramme für die Hochschulmitglieder müssen künftig wesentlich verstärkt werden, um einen hohen Kompetenzgrad im Umgang mit den Neuen Medien zu sichern und Potentiale für den Einsatz von E- Learning in der Hochschullehre zu schaffen. Damit diese Potentiale auch tatsächlich genutzt werden, haben sie die Aufgabe eventuelle Barrieren des Nicht-Könnens, Nicht-Kennens und/oder Nicht-Wollens zu überwinden» (Kretschmer, 2004). ("Further education and qualification programs for university members must be significantly strengthened in the future in order to ensure a high level of competence in the use of new media and to create potential for 
the use of e-learning in university teaching. To ensure that these potentials are actually used, they have the task of overcoming any barriers of not being able, not knowing and/or not wanting to use them").

Organization of learning is a profitable cooperation; since self-defining behavior is stimulated and promoted, in no case it should be spontaneous and chaotic.

In terms of psychology and pedagogy, the social and technical organization of learning smooths complexity of learning, explains how to deal adequately and successfully with new tools and forms of teaching and learning, the main attention of which is given to cognitive aspect.

Thorough analysis of the workload of students in specific learning situation together with organization will exclude unnecessary requirements from educational environment, thus, providing opportunity to purposefully use capabilities of students in order to establish interactive connection of content and to form dynamical interactive presentations in online learning environment. results.

Non-organized learning often takes place in incorrect fashion and leads to non-optimum

\section{Referencias}

Babanskaya, O.M., Mozhaeva, G.V., Serbin, V.A., Feshchenko, A.V. (2015). Sistemnyi podkhod $\mathrm{k}$ organizatsii elektronnogo obucheniya $\mathrm{v}$ klassicheskom universitete [Systematic approach to organization of electronic learning in a classical university]. Otkrytoe obrazovanie, $\square 2: 69$.

Kretschmer, M. (2004). Infrastrukturen für das E-Learning im Hochschulsektor. Campus 2004: Kommen die digitalen Medien. Medien in der Wissenschaft, 29: 412.

Rinn, Ul., Bett, K. (2004). Revolutioniert das „Е“ die Lernszenarien an deutschen Hochschulen? Eine empirische Studie im Rahmen des Bundesförderprogramms „Neue Medien in der Bildung“. Campus 2004: Kommen die digitalen Medien. Medien in der Wissenschaft, 29: 430. 